\title{
Focus groups, community engagement, and researching with young people
}

Book or Report Section

Accepted Version

Lloyd-Evans, S. (2017) Focus groups, community engagement, and researching with young people. In: Skelton, T., Evans, R. and Holt, L. (eds.) Methodological Approaches. Geographies of Children and Young People, 2. Springer, Singapore. ISBN 9789812870193 Available at https://centaur.reading.ac.uk/85877/

It is advisable to refer to the publisher's version if you intend to cite from the work. See Guidance on citing.

Publisher: Springer

All outputs in CentAUR are protected by Intellectual Property Rights law, including copyright law. Copyright and IPR is retained by the creators or other copyright holders. Terms and conditions for use of this material are defined in the End User Agreement.

\section{www.reading.ac.uk/centaur}

\section{CentAUR}

Central Archive at the University of Reading 
Reading's research outputs online 
Lloyd-Evans S. (2017) Focus Groups, Community Engagement, and Researching with Young People. In: Skelton T., Evans R., Holt L. (eds) Methodological Approaches. Geographies of Children and Young People, vol 2. Springer, Singapore

\title{
Contents
}

1. Introduction

2. Critical Reflections on 'Doing' Focus Groups with Young People

3. Journeys between Focus Groups and 'Go alongs'

4. Young People's Participation in Focus Groups: when, where and how:

4.1 Planning and Recruitment

4.2 Facilitating Focus Groups

5. Conclusions

\begin{abstract}
Over the last decade, participatory action research (PAR) has been increasingly used in geography in an attempt to move away from identifying and theorizing problems towards engaging with social action, impact and empowering local communities. Participatory research is seen by many geographers to produce more relevant, non- hierarchical and morally aware forms of social geography and it can act as a 'lever' and subsequent indicator in the cohesion and engagement of young people in community development. Drawing on these debates, this chapter critically explores the use of focus groups and other group-based methodologies with young people through the lens of a participatory action research project undertaken in a 'disadvantaged' neighbourhood in the town of Reading, UK. It explores the ways in which participatory focus groups, and associated group based methods such as 'go-alongs', can offer tools for understanding young people's group behaviours, interactions and norms, particularly as part of a multi-method approach to community-based field research. Using the project as a lens for understanding youth engagement, the chapter also seeks to address the intricacies, complexities and messiness of researching with young people in order to understand how methodologies learned in the classroom can be transitioned to the field. Following a discussion of PAR and community engagement, the chapter critically explores the strengths and weaknesses of using focus groups with young people before examining other more mobile ways of doing group research. It then provides a discussion of the logistics of planning, recruiting and facilitating focus groups and concludes by offering some simple yet effective ways of engaging young people in social action.
\end{abstract}

Keywords: Participatory action research; young people; focus groups; community development; goalongs; social action; public engagement 


\section{Introduction: Engaging Young People in Community Research}

In a community context, there has been a universal move towards more participatory research techniques that attempt to redress issues of unequal power and positionality that can occur whilst undertaking research with 'hard to reach' social groups and young people (Kindon, 2003; Kindon et al, 2007; Cahill, 2007; O'Kane, 2008; Tilleczek, 2011; Blazek et al, 2015). Over the last decade, participatory action research (PAR) has been increasingly used in geography in an attempt to move away from identifying and theorizing problems towards engaging with social action, impact and empowering local communities (Pain and Francis 2003; Kesby 2014; Askins and Pain, 2011; Mason, 2015). Participatory research is seen by many scholars, particularly feminist geographers, to produce more relevant, non- hierarchical and morally aware forms of social geography and it can act as a 'lever' and subsequent indicator in the cohesion and engagement of young people in community development (Kundrani, 2007; Grant 2016). As discussed elsewhere in this collection (see Evans, 2016; White and Tyrrell, 2016) participation inherently implies a two way process whereby information moves between researcher and participants towards a mutual goal of shared knowledge creation and collaboration (Pain, 2004). This approach can disrupt the traditional processes and hierarchies that have shaped the engagement of academia with communities in the past (Pain and Francis 2003), democratise the research process and help dissolve traditional boundaries between researcher and subject (Stringer, 2014). An essential component of participatory research is the careful consideration and acknowledgment that young people hold 'extensive knowledge' about their communities (Torre and Fine, 2006) but exploring and understanding this knowledge remains problematic. This chapter aims to show how doing participatory group based research, particularly focus groups, can offer an informative and potentially empowering tool for gathering community knowledge and engendering youth engagement in local projects.

Until recently, there has been little focus on the relationship between youth engagement and community development in a global North context (Barnett and Baugh, 2007; Jupp, 2008; 2013). This inter-connection has been strained in the past, with adults considering the presence of youths in community and public places 'polluting' and a possible danger to public stability (Cahill, 1990). However, recent trends suggest young people are increasingly visible and active components in community spaces (Brennan, 2008) and their role is changing as they undertake more significant roles in shaping the development of their communities (Huber et al., 2003). Research from the National Centre for Social Research (NCSR) suggests that young people are the primary targets in government recruitment and retention initiatives relating to community based activities such as volunteering (NCSR, 2011) and yet they are often still excluded from real decision making in community development initiatives. Jupp (2013) has identified the need for youth to have 'a sense of community' as a vital component within interventions in community spaces, particularly in more disadvantaged neighbourhoods, and engaging youth in community research activities can provide a pathway for helping young people to shape more inclusive 'senses of community' (Brennan, 2006). Related, is the facilitation of vital links for young people to engage within their own communities (Kegler et al., 2005), enabling them to transition to problem solvers and decision makers (Brennan, 2008). Chawla (2002) identifies many benefits in engaging youth perspectives through research, including the challenges of 
social exclusion, redistribution of youth power and increased capacity of youths to change their lives positively and yet, much community-based research still circumvents young people due to logistical and ethical challenges around finding effective and meaningful methods of participation.

This chapter explores the ways in which participatory focus groups, and associated group based methods, can offer tools for exploring young people's group behaviours, interactions and norms, particularly as part of a multi-method approach to community-based field research. Focus groups, also referred to as 'group depth discussions', are group-based conversations typically lasting from 1 to 3 hours and are conducted with around 6 to 8 participants. Focus groups can be used as a 'stand-alone technique' but they are most commonly employed as part of a multi-method approach to field research (Smithson, 2000). Despite the popularity of the traditional focus group as a tool for researching with youth in a variety of contexts (Krueger and Casey, 2000; Hyams, 2004; Bennett, 2009), there is still a lack of awareness in community research of the diversity of methods offered through participatory group research that extends far beyond the traditional format of a timed group conversation. This chapter seeks to offer insights into more mobile ways of engaging with youth as coproducers of their own knowledge and praxis (Leyshon, 2002; Hastadewi, 2009; Lushey and Munro, 2015). The logistical and emotional challenges of researching with groups of hard to reach young people often call for a more innovative methodological approach than the standard focus group used in many community projects.

Drawing on these debates, this chapter critically explores the use of focus groups and other groupbased methodologies with young people through the lens of a participatory action research project undertaken in a 'disadvantaged' neighbourhood in the town of Reading, UK. Through a community-led research partnership called the 'Whitley Researchers', local sixth formers, resident researchers and undergraduate students worked together to design and operationalize research that explored the everyday travel and mobility experiences of families in South Reading, UK, as part of the Whitley Big Local's $f 1$ million initiative (Lloyd-Evans et al, 2015). This participatory action research project, aimed to explore the everyday mobility needs and experiences of communities in Whitley, identify travel barriers and suggest ways of addressing unmet needs that could be targeted by the Whitley Big Local f1million (a National Lottery initiative). The idea for the research into everyday mobility came from the community as they felt isolated and disconnected from other parts of the town and the author was invited to collaborate in the venture to help shape the research. A further outcome of the project was the development of a new community research training programme and partnership network to tackle isolation and social exclusion. In order to engage with young people in the community, the project sought to train and employ university students, local residents and local sixth formers in designing and creating the research tools. Sixth form students and staff from a local sixth form college in South Reading played a key role in designing the research and offering digital training to University of Reading students on ways of engaging local children and youth in the research via social media. Focus groups and go-alongs were also used as a tool for exploring their views on transport, feelings about everyday life in their community and higher education. An overlapping project, undertaken by one of the University of Reading geography undergraduate student interns in collaboration with third sector organisations in Reading, also explored young people's views of volunteering and views of community development, place and belonging (Aviss, 2016). 
Using the Reading project as a lens for understanding youth engagement in research, the aim of the chapter is not only to highlight the strengths and weaknesses of the focus group methodology but to explore simple yet effective ways of engaging with young people in a wider range of participatory and inclusive collective spaces. Although the focus group remains a core method in understanding group behaviours and attitudes, this chapter will also explore other ways of 'doing' collective research that may be more effective in engaging with young people in different community and cross-cultural contexts. Here, the focus may be on the street or days out through mobile methods such 'go-alongs' or walk alongs' (see also Ponto, 2016) and active group learning in digital spaces. Although methodological literature has, of late, focused on pushing the boundaries of qualitative methods, there has been little consideration of how these ideals play out in practice through lived community research projects. This chapter seeks to address the intricacies, complexities and messiness (Morris-Roberts 2004; Hyams, 2004; Bennett, 2009) of researching with young people in order to understand how methodologies learned in the classroom can be transitioned to methods in practice in the field. It starts with an exploration of the strengths and weaknesses of using traditional focus groups with young people through a brief critique of their application in academic research before exploring other more mobile ways of researching with groups. It then provides a discussion of the logistics of organising and moderating focus groups with young people as part of the Reading participatory action research project.

\section{Critical Reflections on 'Doing' Focus Groups with Young People}

Focus Groups have always been portrayed as a means of generating information on public perceptions and viewpoints (Kitzinger, 1994; Crang, 2001; Hyams, 2004; Krueger, 2008). They can be used as a 'stand-alone' method but they more commonly used as an ancillary method to other qualitative and ethnographic techniques or for triangulation (Laws et al, 2003). The person or researcher that convenes the group interview is often called the moderator, and their role is to facilitate interaction between members of the group rather than control the discussion. In the Reading project, young people and students took turns in moderating and facilitating the group as part of a more participatory and engaged approach to the research ( see also Mistry et al, 2015).

According to Bloor et al (2001: 90), "focus groups have become part of a mixed economy of social research, one component in multi-method strategies, where multiple methods are themselves an emblem of methodological rigour". Focus groups can be used for a wide range of qualitative research aims and objectives, but they are commonly used to ascertain information on collective views of social issues, such as young people's perceptions of crime and violence, to explore group contradictions and uncertainties, or to assess the relative success of a particular strategy or project (Smithson, 2000; Lloyd-Evans, 2008). In a multi-cultural or development context, they can provide data on the meanings that lie behind group assessments and perceptions, or on group processes that underline particular behaviours or viewpoints. The interaction between the group is a key difference from the semistructured interview. What are young people's collective feelings about where they live and how are 
their identities related to place? How do they react to each other when asked to talk about their school or where they live? In summary, focus groups provide a good environment for understanding collective social action and accessing group beliefs, understandings, behaviours and attitudes that might be overlooked in in-depth interviews and questionnaires.

Individual human behaviour is influenced by collective behaviour and thought, and the focus group can be as important as the in-depth interview in understanding the importance of codes of behaviour and 'ways of doing' in relation to a wide range of political, social and economic activities that impact on young people's lives. They are an excellent tool for highlighting the uncertainties, tensions and contradictions that must be played out before 'collective decisions' are reached, and as such they have many advantages in the participatory development process. As Giddens (1991) poignantly argues, understanding the extent to which individual and group identities and motives are influenced by different factors and other social groups is of fundamental importance in social science. In the author's recent research on young people's attitudes towards how a $£ 1$ million investment should be spent in their local community, group discussions highlighted the power of peer pressure and collective views on being stigmatised that shaped, and often constrained, young peoples' ideas about their futures (Lloyd- Evans et al, 2015). Focus groups also provide an occasion for young people to engage in what Bloor et al (2001) call 'retrospective introspection', that is to explore taken for granted assumptions in their everyday lives. It is not uncommon for young participants to speak of how they have never reflected on why they act in a particular way or maintain a daily routine. This reflexivity can often release anxieties and emotions within groups and it's important for community projects to embed opportunities for further discussions and support when needed rather than leaving participants alone to work through the feelings released by a focus group (Bennett, 2009). Thus, the data produced by focus groups can be distinct from that produced by other types of qualitative techniques, but they also have their limitations as will be discussed later.

There are multiple reasons as to why focus groups can be a favoured method for researching with children and youth in a community context (Lloyd-Evans, 2008). Firstly, focus groups are conversational, relaxed and informal in nature and they can be more attractive to young participants than the more intense semi-structured interview. Local secondary school students stated that the word 'interview', is often associated with a stressful situation such as 'seeing the head teacher' or 'applying for a job' and not something they would volunteer to engage in. Young people can also take turns in shaping and facilitating the conversation, which can destabilise traditional power relations and engender a more inclusive feeling. Secondly, children and adolescents often feel more comfortable taking part in research alongside their peers and are more likely to engage in a group event. Although this has its limitations, as we will explore later in the chapter and elsewhere by Punch and Graham (2016) in relation to private spaces of the home, group discussions are often perceived as safer discursive spaces than other methods, particularly for young women and diverse cultural groups. In the Reading project, small focus groups were an effective way of engaging with young Muslim women about their attitudes to travel and mobility as individual interviews were seen as "prying", "too intense" and "intrusive". These young women had rarely been asked for their opinions on how they would like to see their neighbourhood improved. Group discussions are particularly good for 
researching with people whose voices are often missing in policy debates, offering rich and insightful testimonies that can destabilise traditional power relations (Dwyer and Buckle, 2009; White and Tyrrell, 2016). The concept of 'voice' is viewed by many scholars as an expression of power relations (Hyams, 2004) and researchers have argued that the focus groups can be an informal and friendly space for listening and learning from younger participants that have relatively little power. As Reinharz (1988: 15-16) argues "if you want to hear it, you have to go hear it, in their space, or in a safe space..... In other words, if you want someone to tell it like it is, you have to hear it like it is".

Thirdly, group discussions are less focused on an individual's stories and experiences which can be useful when researching sensitive issues as participants can talk about general attitudes or "things that have happened to their friends" rather than themselves. This can be particularly important when researching personal or controversial issues. This broad methodological approach exposes 'private' attitudes in more anonymous environments and can help engage marginalised voices in the 'remaking' of public space (Nagar, 2000). Group discussions can also provide a certain degree of anonymity and safety in numbers. In fact, many of the young people we approached had refused to take part in previous community research as they felt uneasy and intimidated.

Finally, a group discussion can provide both the starting and end points for using a range of participatory and visual techniques that may be more insightful in exploring feelings, attitudes and ideas than just talking, as discussed elsewhere in this collection (Grant, 2016; Blazek et al, 2016). The use of photos, games, videos, performance or social media as 'enabling methods' can provide more powerful and rich data sets than individual conversations alone, particularly in an ethnographic context (Garrett, 2011; Allan, 2012; Farmer and Cepin, 2016; Evans, 2016). In their research in Cambodia, Garrett and Brickell (2015) use participatory video to tackle the often hidden and silenced dilemmas facing young women around domestic violence, though as Kindon (2016) reminds us, researchers should be cautious over claims that using video is always empowering. The use of participatory techniques such as mapping, drawing and creative arts with children and youth are now well-established, particularly in the global South (Kesby, 2007; Evans, 2016). In the Reading project, local sixth-formers and students took it in turns to provide techniques training in methods that would help facilitate a more inclusive working relationship and also contribute to co-producing knowledge. While the undergraduate students took the lead in facilitating groups on writing newspaper articles and data collection, the sixth formers wanted to showcase their digital skills at using video, social media and paperless working. These lively, interactive and 'messy' sessions provided spaces for young local residents to take ownership and lead on aspects of the project that were relevant to them and they particularly enjoyed the fact that they had better digital literacy skills than a bunch of University undergraduates. The group also worked together on producing a reflective blog (see Box 1). These encounters also provided reflective spaces for the geography students to critically reflect on their own journeys through education and how they engaged with communities 'back home'. 
Box 1: Extract from the University's intern's blog: working with local college students to develop digital materials, 2014.

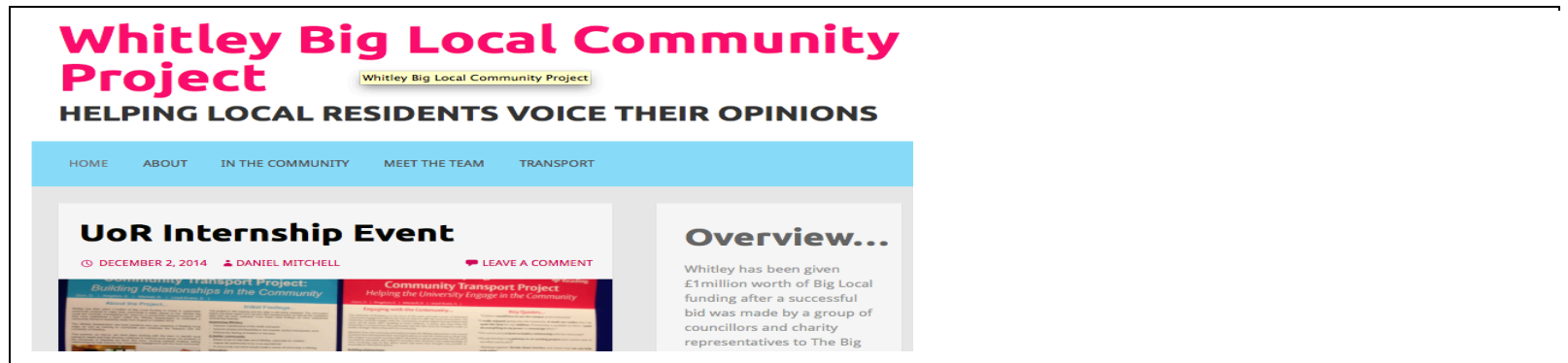

The students at NTA have been working on increasing the use of social media for the project in Whitley and they have created pages on Facebook, Twitter and Instagram. Their primary use is to share information and keep the local community updated with the project but they are also handy for sharing pictures, posting links and sharing our latest ideas. In our meeting with NTA this week, the other student interns and I, shared our own ideas with the students and then worked with them to see how they could be implemented. The ideas for the social media included: 100 days of Whitley, a Whitley project hashtag, regular updates and engaging with the Whitley public.

It has been so interesting working with the girls at NTA and I have learned so much from them already! The school is very tech-savvy and they have told us all about Google+ and Google Drive. Although this is not necessarily directly linked with transport, it has definitely proved useful for communicating with the other interns and Sally. As part of the University and through the internship, I have gained a lot of technical knowledge and insight into the local community.

Working with NTA has been really beneficial for the academy as well and next week, the students at NTA have been invited to the University with the rest of the team working on the Whitley project. This day at the University will involve a talk about University life and research training on focus groups and analysing questionnaire data as well as a tour around the Whiteknights campus.

As with all methods, focus groups have their limitations particularly around the 'messiness' of the data they produce (Bennett, 2009). They are often inappropriate for exploring in-depth individual motivations or behaviours (see Punch and Graham, 2006), and researchers often make the mistake of making assumptions about individual's lives from the stories they tell during group discussions. Secondly, as focus group research is often intended to be participatory and benefit the 'group', it runs the risk of evoking a misguided notion of a 'homogeneous community' or 'group consensus'. It is important to remember that the material collated in focus groups is a reflection of the views of the 
group at that given space and time and they are often subject to wider geopolitical factors. Groups can fail to show the real tensions and contradictions between participants, particularly when dominant or more powerful voices overshadow controversial views. Likewise, it is equally dangerous to hope that focus groups will provide the authentic 'voice of the people' as the group environment can actively shape and alter group understandings in situ (Smithson, 2000). This is particularly relevant when researching with friendship groups, as highlighted in an extract from one of the undergraduate student interns' research diary from a focus group that explored young people's views on community development and volunteering within the Reading Project (Box 2).

Box 2: Extract from field diary, Sam Aviss, September 2015, South Reading (Aviss, 2016).

"What soon became apparent was the effect that other participants had on each other. This was particularly significant within the focus groups, where the 'observer effect' became apparent, whereby participants based their responses on their peer group and what they thought was socially acceptable, or what they had heard before but didn't necessarily know or think. This was especially pertinent amongst teenagers (16-18 years old). A common feature of the quieter participants was agreeing with others, with responses such as "yeah....I agree" and "I would say the same thing". This fear and/or uneasiness of being involved in group discussions can relate to social acceptance and desire to not alienate their peers".

Although focus groups can be useful for researching sensitive topics, problems can arise if the topic is politically volatile or controversial. It is not uncommon for local communities, or powerful individuals, to explicate a different research agenda to that of the external researchers or 'experts'. I have worked on projects in the UK where community leaders have attempted to regulate the research process to serve their own political interests, and focus groups can easily fuel community tensions and even promote unrest and outrage. As the next section will discuss, focus groups can easily be biased through their recruitment, moderation and analysis.

Focus groups are most commonly undertaken at a fixed time and space, maybe in a youth centre or local organisation, but increasing attention focuses on the use of more mobile collective methods that interlink with participant observation. Multi-sited ethnographic ways of researching with youth, such as active participation in activities such as shopping or cooking, playing sport, go-alongs around a neighbourhood or community event or taking part in the journey to school, can also be seen an extension to the collective research toolkit (Busher and Urry, 2009). Plate 1 shows students working on group mapping exercises at the local summer fun day. 
Plate 1: Intern, Emma, 'doing' research at a community fun day

Source: author, 2015

\section{Journeys between Focus Groups and 'Go alongs'}

Understanding the micro-geographies of young people requires use of a variety of techniques that they find culturally credible and that allows them to talk freely about their lives and how they are situated among other narratives (Leyshon 2002; Brown and Durrheim, 2009). Much of the work on 'walk' or 'go-alongs' tends to focus on their role within a multi-sited ethnography where time and space paths are shared by researchers and participants (Evans and Jones, 2011; Ponto, 2016). Kusenbach (2003) defines this type of mobile interview as a 'go-alongs' when:

'researchers accompany individual informants on their 'natural' outings, and - through asking questions, listening and observing- actively explore their subjects' stream of experiences and practices as they move through, and interact with, their physical and social environment.'

(Kusenbach, 2003:463)

Group discussions in-situ or go-alongs (see also Anderson, 2004; Sclater and Lally 2014; Hemming and Madge 2012) provide an opportunity for the researcher to temporarily 'live the life' of participants, unlike traditional focus groups which are stationary. This method can help to re-adjust the balance of power between researcher and participants, as the researcher becomes the follower and relies on the participants to decide where they go and what they reveal. This positioning as a 'novice in a new world' (Anderson and Jones 2009:300) can open up a sharing of everyday lived experience and help young participants illustrate in non-verbal forms the practices of their everyday lives. Context can be demonstrated in a powerful way through this technique, and enable subtle emotive experiences and differences between the participants to become apparent. Go-alongs, as discussed by Ponto (2016) in this volume provide further opportunities for complex geographies of 'growing up' to be uncovered, imagined and contested, particularly when researching issues around belonging, place and identity. Talking to young people on a journey around town can be far more informative than a group chat in a community centre.

When engaging with young people in research projects, it is crucial that methods respect the time commitment of young people and their ability to participate. Joining in activities or outings that are already arranged can be less intrusive. Although 'go-alongs' cannot always replace in-depth participant observation or ethnography in their depth and insight, they can highlight the challenges 
of travelling to a nearby town, or go to college, scheduling around sporadic bus timetables (difficult to access without the internet), and the logistics of caring for a smaller siblings. In this way, dialogues around the challenges of the everyday can come to life. In the Reading project, go-alongs with young parents between the community centre and a children's play area highlighted both material and nonmaterial obstacles that prevented use of the park, such as the difficulties of carrying shopping and toddlers through traffic, litter and anxiety over safety, that brought the 'everyday' into the lives of the researchers.

More mobile ways of working with young people bring their own challenges and it is also important to recognize the challenges and weaknesses associated with go-alongs or walk-alongs (Woods 2010; Lew 2011; Busher and Urry, 2009). Despite being a useful methodological technique in eliciting detail on everyday lives, it is also highly subjective and open to interpretation by the researcher. It's more difficult to record group conversations on the go and therefore, go-alongs require the research to collect and record data in different ways. The lack of traditional transcripts for analysis can raise concern over the validity of the data. For example, critiques of a doctoral researcher's reliance on go-alongs and group outings as their main methods for researching with teenage parents (Foy-Phillips, 2014) raised important and timely debates over what constitutes 'authentic' and 'proper' research within social science. Although, Foy-Phillips (2014) found that accompanying young parents to supermarkets, children's services or the park offered a more meaningful and insightful way of exploring their everyday lives, feelings and aspirations, such methods are often criticised as less rigorous as the data is often more 'messy' than an interview transcript (Bennett, 2009). Other scholars have interrogated the ethical questions around participants' emotions during mobile research, the extent to which they may feel pressurised or stressed, or unable to 'leave' the go-along if they felt uncomfortable or uneasy (Hadfield-Hill and Horton, 2014; Ponto, 2016). These dilemmas are not easily solved but participatory approaches to co-producing the research with participants can help build the trust and emotional security that helps to create a more inclusive research space where such ethical challenges can be discussed and where participants feel empowered to question, change the research or walk away when it suits them.

Illustrating vignettes of participants' lives, taking photos and the intensive use of voice recorder field diaries that allow the reader to draw their own conclusions about the research, can also help address power imbalances. Increasingly, new ICTS are offering new exciting and dynamic ways of recording experiences and collecting data that can be discussed in a more traditional focus group setting later on. Mobile voicemail and video is much easier now due to capacity of mobile phone technologies and social media (see Ponto, 2016). There are new Apps for mapping group outings and recording places of significance but in reality, the challenges of this approach included writing complete notes both during and after the interviews, as well as ensuring that they accurately reflected the commentary, particularly in a group context. Overall, many researchers believe that the benefits of increased participation of young people in mobile group methods outweigh the limitations of the challenges associated with not having traditional transcripts of the discussions to analyse. In many cases the strengths and challenges are one and the same (DeLyser and Sui 2013) and they tend to be similar to 
the weaknesses of more traditional focus groups in terms of data analysis, the politics of voice and group consensus (see Table 1).

Table 1 - Strengths and Limitations of Using Focus Groups with Young People

Strengths

They generate excellent data on group views, beliefs and reasons for collective action

Groups can be participatory and empowering as participants' find strength in numbers and feel in control of the research process

Good for discussing sensitive topics amongst people whose lives are influenced by the same issue

They can lead to collective action as a result of people sharing their experiences

A good platform to use PRA/PLA techniques such as rankings, mapping and other visual methodologies

Can generate rich and abundant data

Accessible to people who have literacy difficulties
Limitations

Evoke misguided notions of a collective or community consensus

Groups can be subject to peer

pressure and dominated by powerful

'voices' - controversial views can be silenced

Not good for understanding individual motivations

Recruitment can be difficult, timeconsuming and unsuccessful Moderation/facilitation is a skilled technique and requires practice

Data can be difficult to analyse

Source: adapted from Laws, Harper and Marcus, 2003; Lloyd-Evans, 2008 


\section{Young People's Participation in Focus Groups: when, where and how}

As previously discussed, focus groups and more mobile methods such as 'go-alongs' are often used as an adjunct to a range of qualitative field research methods. In circumstances where in-depth ethnographic work is likely to be difficult (and infeasible), due to time restrictions or safety in the field, then focus groups will provide the researcher with some insight into community relations, identities and understanding group feelings about a particular topic. However, it is important to understand that as atypical, controversial or extreme opinions are less likely to be explored in a group situation, focus groups are best used alongside other qualitative methods, such as individual in-depth interviews or participant observation (Krueger, 2008). Focus groups are commonly introduced at three different phases of a research project, but there are no set rules for their application.

Firstly, they can play an invaluable role in gaining co-produced information on a research topic or provide an overview for more in-depth ethnographic research. They are frequently used in pre-pilot studies to explore issues that require further examination or to gain background data on a particular issue. The stories and anecdotes that invariably come from group discussions can provide rich material for devising questions for in-depth interviews or for defining research objectives. They can also be used to explore differences in the use of language and vernacular terms that social groups feel most comfortable with. When conducting research with teenagers, for example, is it appropriate to use slang or will it offend anyone? These questions are also adequately explored in pilot studies for indepth interviews, but the focus group can sometimes offer a more accessible method when time in the field is limited.

Secondly, as focus groups encourage a 'reflexive capability' (Bloor et al, 2001), they are often employed to qualify or explore issues in depth that have been raised elsewhere in the research process, maybe in a more structured survey. They are an excellent tool for gauging young people's attitudes to events, campaigns, policies and social issues such as evaluating attitudes to the use of mobile phones in public spaces (see Conradson, 2005).

Thirdly, and as in the Reading project, focus groups are often used to engender co-public participation as part of Participatory Action Research (PAR) and are commonly used to facilitate public and community participation in development projects (Mosse, 1994). They can offer an effective tool in communicating research agendas and findings with communities in order to encourage groups to take ownership of the research and co-produce outputs. The focus group is often the starting point for the use of PAR methods, but it is important to note that focus groups are not always participatory as they can be facilitated in a non-reflexive and controlled manner that regards group participants as passive objects. Studies argue that the inclusion of young people as partners in research shows them as 'agents of change' (Ginwright and James, 2002), highlighting that listening to young people is fundamental in encouraging participation in social change.

Community-led participatory research relies on careful design and it is important to set aside sufficient time for the selection, recruitment and organisation of the groups. This process can be a lengthy and 
complicated experience, particularly if the methodology involves co-producing data and knowledge in collaboration with local communities. Engaging with young people can be particularly challenging if young people feel excluded from existing community spaces and researchers may need to work with local organisations and institutions as a starting point. In the Reading project, local organisations played an important role in working with the undergraduate interns in a range of community events to help them engage with young residents (see Plate 2).

\section{Plate 2: Undergraduate interns, Daniel, Danni and Beth presenting their community research}

Source: Author, 2014

\subsection{Planning and Recruitment}

Focus groups are not determined through a random sampling technique, so there are a number of basic issues that the researcher needs to consider when recruiting participants (Smithson, 2000). As group interaction is the main advantage of the focus group method, the researcher must carefully consider the social composition of the group. For example, would it be better to convene groups of a similar age, ethnicity or gender? Groups can be convened on a wide range of social criteria such as age, gender, religion, ethnicity, occupation, a shared interest, life-stage or geography. Is the research aimed at understanding a wide range of viewpoints or is it hoping for some group consensus on a particular issue? Here, issues of power and social status must also be considered if the researcher wants to encourage participants to speak freely.

There are no set rules for the recruitment of focus groups as there are many contradictory processes that shape the social dynamics of group interactions. Focus groups can consist of strangers or of preexisting social groups based on family or kinship ties, social or community networks such as churches or cooperatives. The use of pre-existing groups will be advantageous if the research is exploring a sensitive topic, or if a particular characteristic is the basis of membership of a group, such as a disability or medical condition (Laws et al, 2003). Young people are more likely to turn up to a focus group if they are in the company of friends, but peer pressure is more likely to shape the dynamics of such a group (Bennett, 2009). Pre-existing groups can also be problematic, particularly in community situations where participants may not want friends or neighbours to 'know their business'. In the Reading research, the majority of the young participants wanted their participation in the Reading projects to remain anonymous due to concerns over potential stigmatisation in the neighbourhood. Although video and visual methods were used in the groups, they did not want photos or video clips to be publically available so this chapter only contains photographs of the University interns. The use of photos in disseminating local community-based research raises many ethical issues around 
confidentiality and researchers must ensure that they seek permissions from participants to include photographic material.

One of the Reading focus groups consisted of mainly Muslim female students from the same college programme as they felt more comfortable talking in a single gender group (Hyams, 2004). These structures ensured that women were comfortable among their peer groups in terms of their levels of experience and would feel able to contribute freely to the discussions. The author has convened mixed gender groups of teenagers only to find that some male members of the group intimidated female participants but this depends on the context of the research and issues to be explored. Diversity might encourage spirited debate, but it can also lead to conflict and contradiction. Conducting a focus group with participants from rival schools or neighbourhood groups, for example, will probably fail to produce any meaningful discussion and may even result in confrontational behaviour. Such methodological considerations are paramount to the success of focus group research and other collective methods.

In participatory research, where there is usually a community focus, participants are often recruited from local networks, clubs, sports groups or existing social groups. In the wider Reading Project, local residents were employed as co-researchers and trained to undertake the research themselves but this is not always possible. Another effective strategy can be recruitment through an intermediary, such as a community leader or teacher, but the researcher must ensure than research ethics and positionalities are subject to critical reflection. In South Reading, many team meetings have been spent discussing the ethical issues of using local facilitators (see Mistry et al, 2015), the researcher's positionalities and how their situated identities shifted during the course of the project. Focus groups can be time-consuming to organise and there will always be occasions where participants will not show up. Consideration must also be given to where and when the groups will be held. Familiar, but neutral, quiet meeting places such as sports centres are usually a good place to convene groups. In the Reading project on community participation, some focus groups were held in local schools with teachers present and it was interesting to note that students appeared to be quieter and more constrained under the watch of their teachers than in the community settings. Similar consideration should also be given to the timing of the focus group as not to place participants in a time stressed situation.

The use of incentives in research has been subject to debate but it is increasingly recognised that researchers as good ethical practice for researchers to value their participants' inclusion in a research project by offering an incentive or gift of some kind, particularly in lower income communities in which people's time is limited by income earning activities. In the UK, it is common for respondents to be given book tokens or vouchers as a token of appreciation. In a development context, views on the appropriateness of incentives are varied; while some view this as an ethical responsibility to thank people for their time and contribution to the research (Evans, 2016), some researchers and NGO staff are apprehensive about this, particularly when recruiting only a small number of participants and where resources are limited. Who do you leave out? This is a matter for personal consideration in the field, and experiences will be different depending on the research context. In the Reading project, 
young people were given a voucher to use in a local shopping centre as a way of thanking them for facilitating and participating in the project.

\subsection{Facilitating Focus Groups}

In the early phase of the Reading study, focus groups were used to inform and include communities in designing the research questions and training participants in research techniques, such as focus group facilitation and digital skills. Group discussions centred on key topics around education, social isolation and mobility, and generated contextual data such as stories, rumours or historical references, all of which were valuable to the research. From the outset, the project was two-way; sharing and disseminating knowledge and experiences with events held at both the College and University, as well as in the local community. 'Go-alongs' around the community and University campus were a good way to get to know each other but became clear from the outset, that young people felt more comfortable and engaged with the students than the University staff and other adults. Group discussions moderated by 19 year old undergraduates were more successful in encouraging younger participants to talk about their feelings and reflect on their experiences even though they came from different ethic and social backgrounds. Furthermore, group research is also influenced by individual social and emotional qualities, 'personalities rather than positionalities' (Moser 2008:383) of the researcher as well as other social signifiers such as gender and generation. These factors can significantly alter the way in which research participants engage with a researcher. In reality, not all researchers will produce the same findings as their unique individual biographies affect their 'way of seeing' and understanding of the world. Definitions of personality vary and generally stem from psychology, focusing on particular aspects such as being enduring, distinctive in terms of patterns of behaviour, thoughts and emotions, and characterising thoughts, feelings and behaviours that distinguish one person from another. In short, they affect how people respond across different situations (Moser 2008; McAdams and Pals 2006) as social identities that are highly dependent on context.

It is standard practice for researchers to devise a discussion guide for moderating the group. This can be as structured or informal as desired, but it is always a good idea to think about key questions, activities and issues to be raised in the discussion. In the Reading project, student interns and sixth formers co-produced the discussion guides, taking it in turns to facilitate groups and jointly exploring their knowledge of, and attitudes to, mobility and use of neighbourhood space, opportunities and barriers that shaped their everyday feeling of belonging and views on where improvements might be targeted. In some instances, stimulus material such as display boards, vignettes, images, video or music can be used to provoke discussion. As discussed earlier, focus groups can also provide a good environment for more innovative participatory techniques during the session and it is often a useful idea to encourage participants to put their ideas on paper, draw images or maps, devise flow charts, respond to images, take their own photographs with disposable cameras, or use ranking exercises (Farmer and Cepin, 2016). Visual exercises and games provide a focus for talking about issues and they also play a useful role in encouraging quieter members of the group to take part in the research, as highlighted in Plates 3 and 4 where young parents mapped their everyday mobility experiences. 
Plate 3: Young parents maps of their everyday journeys

Source: Lloyd-Evans et al (2015)

Plate 4: 'Going to the park': Observations following a 'go-along'

Source: Author, 2015

There are no set procedures for moderating focus groups with young participants but there are a few basic principles that will help facilitate a successful group discussion and enable the group to gain agency over the process. As part of the research training, participants discussed different ways of doing focus groups and Box 3 provides a basic set of guidelines used in the Reading project for the planning and moderation of focus groups. It is often helpful to remind participants that they should feel free to be able to debate, disagree and critique, and that there is no right or wrong way of thinking. Participants should be asked to introduce themselves to the group. It is usual for the introductory discussion to evolve around a familiar background issue in order to make the group feel at ease. It is usual to start with 'how' questions that allow all members to make a contribution before moving onto more sensitive or difficult 'why' questions when more confident and empowered. Ethical considerations in focus groups are similar to those presented in other research methods, such as the in-depth interview. Groups are perceived to be a conducive environment in which to discuss a sensitive issue, such as violence, on the premise that people feel more relaxed and communicative amongst friends. The ethical issue here is not whether the group encourages frank discussion but whether such a discussion in an open forum is in the interests of the participants or whether individuals feel intimidated or uncomfortable with the topic. In her interesting discussion on the 'politics of voice', Hyams (2004) encourages facilitators to give as much attention to 'listening' to the silences, awkward gaps and hesitant moments, than the dialogue. A good moderator is one who facilitates discussion among the respondents but who does not dominate or lead the group, although this can be difficult if participants are reluctant to talk as highlighted in Box 4. 
Box 3: A Quick Guide to Focus Groups (adapted from Laws, Harper and Marcus, 2003; Lloyd-Evans, 2008)

Location - find a suitable safe neutral space that young people will feel safe and comfortable with

Difference and Diversity - social composition is of paramount importance; think about whether it's appropriate to use existing groups who know each other or strangers, single or mixed gender and ethic groups, participants of similar age/generation or lifestage.

Quantity of Groups - a single focus group will rarely be sufficient to provide a valid representation of people's points of views, somewhere between $4-8$ groups is often appropriate

Ethics and Consent - similar to other methods of researching with young people but remind participants about their obligations regarding confidentiality of the stories raised; it's useful to talk about this at the start.

Researcher's Approach - make people feel at ease with an informal and pleasant approach - this is not a test; co-produce the discussion schedule and take it in turns to facilitate different activities

Focus Group Schedule - plan how you will structure the group; what questions will you ask?; what activities or games can you include?; don't forget to plan any resources; mobile methods such as go-alongs may be more appropriate and engaging

Participants - encourage everyone to participate and give them equal chances to speak; pay attention to groups dynamics, body language and silences as well as the conversation

Peer-pressure - try to stop dominant members of the groups from pressurising others to agree with their viewpoint and encourage the quieter voices; games and exercises are useful ways of engaging

Data - remember that data comes in many forms and can include visual and digital forms; the data collected relates to the group and not individuals - don't attempt to start pulling out individual stories as you may get it wrong

Analysis - transcription of focus groups discussions is time consuming and data produced from go-alongs can be hard to record and 'messy - keeping a reflective field diary, videos, pod-casts and other visuals methods are useful. Co-production involves reflecting and analysing the data with the participants

Dissemination - an end of project group is a good way to discuss findings and ways of presenting the research to the wider community; continue to engage young people in any further projects or social action that results from the project 
Box 4: Extract from field notes from a focus group with teenagers about attitudes to community volunteering in South Reading (Aviss, 2016).

"Some respondents did not give sufficient responses, prompting me to facilitate and lead the discussion, often suggesting something in order to set up a response or dialogue. I had to take care when doing this so as not to upset or unfairly influence the answers given. The final limitation evident was the large amount of dialogue produced and the technical limitations that came with using a Dictaphone. This was particularly prominent in the focus groups, with the larger amount of participants (3-7) interacting, sometimes all at once, at varying times and with different volumes, often making it hard to decipher and making transcribing an even more time consuming process. This all had an impact on the analyses of my data".

The moderator should also keep an eye on the group, try to involve members and make sure that any 'group consensus' is valid for all participants. Involving the participants in the data analysis and dissemination is also essential in participatory approaches (Evans, 2016). In comparison to other methods, focus groups can be particularly difficult to analyse and they present challenges in terms of the management, organisation and analysis of data. Analysis of data should draw on established qualitative methods, but researchers must be aware that focus group data are unique because the group, and not the individual, is the unit of analysis (see Laws et al, 2003 and Conradson, 2005 for good discussions of analysing qualitative field data).

\section{Conclusion}

Recently, there has been growing interest in participatory research and co-production amongst geographers (Pain, Kesby and Askins, 2011; Pain and Raynor, 2016). Yet, despite the excellent contributions made by children's geographies there remains a greater need for policy approaches that motivate and empower young people to actively participate in community decision-making and social change. This chapter has drawn on a community led PAR to show how focus groups and other collective methods can actively engage young people in the everyday matters that affect them. It has suggested that they are also useful in demonstrating that there is rarely such a thing as a single 'community viewpoint' which can be universally applied in public social policy. Focus groups can be particularly powerful in engendering transformation if they are embedded within in-depth ethnographic and participatory fieldwork as they can provide important spaces for enabling young people to be listened to. However, as the students and community researchers in the South Reading project have learned together, focus groups can be challenging, and difficult to design, facilitate and analyse. Ultimately, one of the greatest challenges for the focus group researcher is to find ways of incorporating focus group methods into truly participatory research and development. 


\section{Acknowledgements}

The author would like to thank the young people from South Reading and students/staff from Northumberland Training Academy and the University of Reading interns for participating in the research and the 'Whitley Researchers', Whitley Big Local, the Whitley Community Development Association, the University of Reading and Reading Voluntary Action for their funding, guidance and support.

\section{References}

Anderson, J. (2004). Talking whilst walking: A geographical archaeology of knowledge. Area, 36 (3), 254-261.

Anderson, J., and Jones, K. (2009). The difference that place makes to methodology: uncovering the 'lived space' of young people's spatial practices. Children's Geographies, 7(3), 291-303.

Askins. K and Pain. R (2011), 'Contact Zones: Participation, Materiality and the Messiness of Interaction'. Environment and Planning D: Society and Space, 5, 803-821.

Aviss, S. (2016) The socio-spatial limitations that affect young people's participation in community development, with particular focus on Whitley, South Reading. Dissertation presented for BSc. Human Geography, University of Reading.

Barnett. R and Baugh. E (2007), Youth as central players in community development: Implications and possibilities for extension'. Journal of Extension, 45 (4).

Bennett, K. (2009) Challenging emotions. Area, 41 (3), 244-151

Blazek, M., Smith, F. M., Lemešová, M., \& Hricová, P. (2015). Ethics of care across professional and everyday positionalities: The (un)expected impacts of participatory video with young female carers in Slovakia. Geoforum, 61, 45-55.

Blazek, M. (2016) Participatory Video with Children and Young People. In Evans, R. and Holt, L. (Eds.) Methodological Approaches. Vol.2, in Skelton, T. (Ed.-in-Chief) Geographies of Children and Young People. Springer Singapore.

Bloor, M., Frankland, J., Thomas, M. and Robson, K. (2001) Focus Groups in Research. London: Sage.

Brennan. A (2006) The development of community in the West of Ireland: A Return to Killala twenty years on. Journal of Community Development ,42 (3), 330-374.

Brennan. A (2008), 'Conceptualizing resiliency: An international perspective for community and youth development'. Child Care in Practice, 14 (1), 55-64.

Brown, L., \& Durrheim, K. (2009). Different kinds of knowing: Generating qualitative data through mobile interviewing. Qualitative Inquiry, 15(5), 911-930. 
Busher, M. and Urry, J. (2009) Mobile methods and the empirical. European Journal of Social Theory, 12 (1), 99-116.

Cahill. C (2007) Doing research with young people: Participatory research and the rituals of collective work. Children's Geographies, 5 (3), 297-312

Cahill. S (1990) Childhood and public life: Reaffirming biographical divisions', Journal of Social Problems, 37, 390-402.

Chawla. L (2002) Growing up in an Urbanizing World. London: EarthScan.

Conradson, D. (2005) Focus groups. In R. Flowerdew and D. Martin (eds.), Methods in Human Geography: A Guide for Students Doing a Research Project. Harlow: Pearson, Chapter 8.

Crang, M. (2001) Filed work: making sense of group interviews. In Limb, M. and Dwyer, C. (eds.) Qualitative methods for geographers: issues and debates. London: Arnold.

DeLyser, D. and Sui, D. (2013). Crossing the qualitative-quantitative divide II: inventive approaches to big data, mobile methods, and rhythmanalysis. Progress in Human Geography, 37, 293-305.

Dwyer, S.C and Buckle, J.L. (2009) The space between: on being an insider-outsider in qualitative research. International Journal of Qualitative Methods, 8 (1),54-63

Evans, R. (2016) Critical reflections on participatory dissemination: Co-producing research messages with young people. In Evans, R. and Holt, L. (Eds.) Methodological Approaches. Vol.7, in Skelton, T. (Ed.-in-Chief) Geographies of Children and Young People. Springer Singapore

Evans, J., \& Jones, P. (2011). The walking interview: Methodology, mobility and place. Applied Geography, 31(2), 849-858.

Farmer, D, and Cepin, J. (2016) Creative visial methods on research with children and young people. In Evans, R. and Holt, L. (Eds.) Methodological Approaches. Vol.2, in Skelton, T. (Ed.-in-Chief) Geographies of Children and Young People. Springer Singapore.

Foy-Phillips, P. (2014) Young parenting in rural space: the reproduction of parenting cultures through government policy and everyday practice. PhD Thesis, University of Reading.

Garrett, B. L. (2010) Videographic geographies: using digital video for geographic research. Progress I Human Geography 35 (4), 521-541.

Garrett, B. L. and Brickell, K. (2015) Participatory politics of partnership: video workshops on domestic violence in Cambodia. Area, 47, 230-236.

Giddens, A. (1991) Modernity and Self-Identity: Self and Society in the Late Modern Age. Cambridge: Polity.

Ginwright, S. and James, T. (2002) From assets to agents of change: social justice, organisations and youth development. New Directions for Youth Development 96, 27-46.

Grant, T. (2016) Participatory Research with Children and Young People: Using Visual, Creative, 
Diagram, and Written Techniques. In Evans, R. and Holt, L. (Eds.) Methodological Approaches. Vol.2, in Skelton, T. (Ed.-in-Chief) Geographies of Children and Young People. Springer Singapore.

Hadfield-Hill, S., \& Horton, J. (2014). Children's experiences of participating in research: Emotional moments together? Children's Geographies, 12(2), 135-153.

Hastadewi, Y. (2009). Participatory action research with children: Notes from the field. Children's Geographies, 7(4), 481-482.

Hemming, P. J. and Madge, N. (2012). Researching children, youth and religion: identity, complexity and agency. Childhood, 19, 38-51.

Huber. M. S. Q, Frommeyer. J, Weisenbach. A and Sazama. J (2003) Giving youth a voice in their own community and personal development. Thousand Oaks, CA: Sage.

Hyams, M. (2004) Hearing girl's silences: thoughts on the politics and practices of a feminist method of group discussion. Gender, Place and Culture 11 (1), 105- 119.

Jupp. E. (2008), 'The Feeling of Participation: Everyday Spaces and Urban Change', Geoforum, 39 (1), 331-343.

Jupp. E. (2013), 'I Feel more at Home Here than in my Own Community: Approaching the Emotional Geographies of Neighborhood Policy'. Critical Social Policy, 33 (3), 532-553.

Kegler. M, Oman. R, Veskely. S Mcleary. K, Aspy. C, Rodine. S and Marshall, L. (2005) Relationships among youth assets and neighborhood and community resources. Health - Education and Behavior, 32 (3), 380-397.

Kesby M (2007) Participation as a form of power: retheorising empowerment and spatialising Participatory Action Research. In S. Kindon, R. Pain and M. Kesby (eds.) Participatory action research approaches and methods : connecting people, participation and place. London: Routledge

Kesby, M., Kindon, S. and Pain, R. (2005) 'Participatory approaches and diagramming techniques'. Chapter 9 in Flowerdew, R. and Martin, D. (eds.) Methods in Human Geography: A guide for students doing a research project, Pearson, Harlow, Essex, 144-165.

Kindon, S. (2003), Participatory video in geographic research: a feminist practice of looking?. Area, 35 : 142-153.

Kindon, S. (2016), Participatory video as a feminist practice of looking: 'take two!'. Area. doi:10.1111/area.12246

Kindon, S., Pain, R. and Kesby, M.(2007) (eds). Participatory action research approaches and methods: connecting people, participation. London: Routledge

Kitzinger, J. (1994)The methodology of focus groups: the importance of interaction between research participants. Sociology of Health and IIIness, 16, 103-121.

Krueger, R. (2008) Focus Groups: A Practical Guide for Applied Research. London: Sage. 
Krueger, R.A. and Casey, M. (2000) Focus Groups: A Practical Guide for Applied Research. London: Sage.

Kundrani. A. (2007) The End of Tolerance: Racism in 21st Century Britain. London: Pluto Press.

Kusenbach, M. (2003). Street phenomenology. The go-along as ethnographic research tool. Ethnography, 4(3), 455-485.

Laws, S., Harper, C. and Marcus, R. (2003) Research For Development, London: Sage

Lew, Alan A. (2011). Research methods in geography. International Planning Studies, 16,194-196.

Leyshon. M (2002), 'On being in the field: Practise - progress and problems in research with young people in rural areas'. Journal of Rural Studies, 18, 179-191.

Lloyd-Evans, S., Zishka, L., Mitchell, D., Dorn, D., Kingdom, E., Lacy, E,, Bowerman-Wyatt, E., McSevney, M., Duval, S., Bennett, N., Bradbury, R., Saidykhan, F., Northumberland Training Academy and Ord, J. (2015) Working Better with Whitley: Exploring the everyday needs and transport experiences of local communities in South Reading. University of Reading and the Whitley Big Local. Available from http://localtrust.org.uk/assets/images/uploads/Whitley_Report_25.09.2015_FINAL_VERSION.pdf

Lloyd-Evans, S. (2008) Focus groups. In Desai, V. and Potter, R.B. (eds) Doing Development Research. London: Sage.

Lushey, C. J., \& Munro, E. R. (2015). Participatory peer research methodology: An effective method for obtaining young people's perspectives on transitions from care to adulthood? Qualitative Social Work, 14(4), 522-537.

McAdams, D. P., \& Pals, J. L. (2006). A new big five: fundamental principles for an integrative science of personality. American Psychologist, 61(3), 204.

Mason, K. (2015) Participatory action research: Coproduction, governance and care. Geography Compass, 9, 497-507.

Mistry, J., Berardi, A., Bignante, E., \& Tschirhart, C. (2015). Between a rock and a hard place: Ethical dilemmas of local community facilitators doing participatory research projects. Geoforum, 61, 27-35.

Morris-Roberts, K. (2004). Colluding in" compulsory heterosexuality"? Doing research with young women at school. In Harris, A. (ed.). All about the girl: Culture, power, and identity. London and New York: Routledge.

Mosse, D. (1994) Authority, gender and knowledge: theoretical reflections in the practice of participatory rural appraisal. Development and Change 25, 497-526.

Moser, S. (2008). Personality: a new positionality? Area, 40(3), 383-392.

Nagar, R. (2000) Mujhe Jawab Do! (Answer me!): Feminist Grassroots Activism and Spaces in Chitrakoot (India), Gender Place and Culture 7 (4), 341-362.

National Centre for Social Research (NCSR) (2011) Public Zone - Formative Evaluation of $v$ - The National Young Volunteers' Service. Final Report, Institute for Volunteering Research, University of 
Southampton and University of Birmingham, London.

O'Kane, C. (2008). The development of participatory techniques; facilitating children's views about decisions which affect them. In P. Christensen \& A. James (Eds.) Research with children: Perspectives and practices. Abingdon: Routledge.

Pain. R (2004) Social geography: Participatory research. Progress in Human Geography, 28 (5), 652-663.

Pain, R., Kesby, M., \& Askins, K. (2011). Geographies of impact: Power, participation and potential. Area, 43(2), 183-188.

Pain, R. and Raynor, R. (2016) "A soup of different inspirations": co-produced research and recognising impact as a process, not an outcome. Impact of Social Sciences Blog (28 Jan 2016) Blog Entry.

Pain, R. and Francis, P. (2003), Reflections on participatory research. Area, 35: 46-54.

Ponto, H. (2016) Ethical complexities of mobile interviews with young people. In Evans, R. and Holt, L. (Eds.) Methodological Approaches. Vol.2, in Skelton, T. (Ed.-in-Chief) Geographies of Children and Young People. Springer Singapore.

Punch, S. and Graham, E. (2016) Interviewing children at home: Exploring the use of individual and focus group interviews. In Evans, R. and Holt, L. (Eds.) Methodological Approaches. Vol.2, in Skelton, T. (Ed.-in-Chief) Geographies of Children and Young People. Springer Singapore.

Reinharz, S. (1988) The concept of voice. Paper presented at Human Diversity: perspectives on people context, University of Maryland.

Sclater, M. and Lally, V. (2014). The realities of researching alongside virtual youth in late modernity: creative practices and activity theory. Journal of Youth Studies, 17, 1-25.

Smithson, J. (2000) Using and analyzing focus groups: limitations and possibilities. International Journal of Social Research Methodology 3 (2), 103-119.

Stringer, E.T. (2014) Action Research. London: Sage.

Tilleczek, K. (2011). Approaching youth studies: Being, becoming, and belonging. Toronto: Oxford University Press Canada.

Torre, M. E. and Fine, M. (2006) Participatory Action Research (PAR) by Youth. In Sherrod, L. (ed) Youth Activism: An International Encyclopedia. Westport, CT: Greenwood Publishing Group.

Valentine. G (2008), 'Living with Difference: Reflections on Geographies of Encounter', Progress in Human Geography. Volume 32 (3), pp. 323-337.

White, A. and Tyrrell, N. (2016) Research with children seeking asylum in Ireland: Reflecting on silences and hushed voices. In Evans, R. and Holt, L. (Eds.) Methodological Approaches. Vol.2, in Skelton, T. (Ed.-in-Chief) Geographies of Children and Young People. Springer Singapore.

Woods, M. (2010). Performing rurality and practising rural geography. Progress in Human Geography 34, 835-846. 
